\title{
PELATIHAN PEMBUATAN MEDIA PEMBELAJARAN BERBASIS ANIMASI PADA SMK NEGERI 1 AIR JOMAN - KISARAN
}

\author{
Suci Andriyani ${ }^{1}$, Tika Christy ${ }^{2}$ \\ Program Studi Sistem Informasi, STMIK Royal Kisaran \\ email: suciandriyani94@gmail.com, tikachristy.royal@gmail.com
}

\begin{abstract}
Teachers as educators in general must be able to pass on information and knowledge to students with a clear method and with sufficient acceptability, so that the learning process can run well. For an educator the need for mastery of technology is something that must be mastered in order to support the learning process. In this devotion activity was given training learning and making animation-based learning media to teachers in SMK N 1 Air Joman which was held on December 20 and 21, 2017. it is hoped that the learning and teaching activities will become more interesting and interactive.
\end{abstract}

Keywords: animation,learning media, teachers

\begin{abstract}
Abstrak: Guru sebagai pendidik pada umumnya harus dapat meneruskan informasi dan pengetahuan kepada peserta didik dengan metode yang jelas dan dengan akseptabilitas yang cukup, sehingga proses pembelajaran dapat berjalan dengan baik. Bagi seorang pendidik kebutuhan akan penguasaan teknologi merupakan hal yang harus dikuasai guna mendukung proses pembelajaran. Pada kegiatan pengabdian ini diberikan pembelajaran pelatihan dan pembuatan media pembelajaran berbasis animasi kepada guru-guru di SMK N 1 Air Joman yang dilaksanakan pada tanggal 20 dan 21 desember 2017.Dari hasil evaluasi pembelajaran dinilai bahwa pembelajaran ini memberikan manfaat dalam menambah pengetahuan baru bagi guru dan diharapakan kegiatan belajar dan mengajar menjadi lebih menarik dan interaktif.
\end{abstract}

Kata Kunci: animasi, media pembelajaran, guru-guru

\section{PENDAHULUAN}

Pengabdian Kepada Masyarakat merupakan suatu media untuk menjembatani dunia pendidikan dengan masyarakat, dimana Perguruan Tinggi dihadapkan pada masalah bagaimana agar stakeholder mampu menghadapi tantangan lebih jauh ke depan di era globalisasi. Perkembangan teknologi saat ini juga memberikan banyak dampak terhadap dunia pendidikan terutama dibidang pembelajaran untuk siswa yang lebih interaktif agar memberikan minat belajar, sehingga guru diharapkan mampu menggunakan teknologi yang ada saat ini, maka dari pada itu tujuan kegiatan pengabdian ini adalah untuk memberikan pelatihan pembuatan media pembelajaran berbasis animasi kepada guru-guru SMK Negeri 1 Air Joman.

Proses pembelajaran tidak terlepas dari penerapan teknologi sebagai salah satu langkah untuk menjaga kualitas dan 
Available online at http://jurnal.stmikroyal.ac.id/index.php/jurdimas

keberhasilan proses tersebut. Dengan bantuan komputer dan perangkat lunak yang ada, maka proses pembelajaran dapat dilaksanakan secara efisien dan tepat sasaran. Terlebih lagi, peserta didik yang diposisikan sebagai subjek dalam proses belajar-mengajar akan sangat terbantu oleh computer based learning.

Guru sebagai pendidik pada umumnya harus dapat meneruskan informasi dan pengetahuan kepada peserta didik dengan metode yang jelas dan dengan akseptabilitas yang cukup, sehingga proses pembelajaran dapat berjalan dengan baik. Bagi seorang pendidik kebutuhan akan penguasaan teknologi merupakan hal yang harus dikuasai guna mendukung proses pembelajaran, agar tujuan pendidikan pada umumnya dapat tercapai yaitu mencerdaskan kehidupan bangsa. Meningkatkan hasil belajar adalah aspek yang perlu diperhatikan guru dalam proses pembelajaran yang terjadi di dalam kelas. Guru sebagai fasilitator pembelajaran hendaknya mencari solusi bagaimana caranya media pembelajaran apa yang harus digunakan agar proses belajar-mengajar dapat berjalan dengan menyenangkan dan dapat memudahkan siswa dalam menerima materi. Media pembelajaran sebagai sumber belajar merupakan suatu komponen sistem pembelajaran yang meliputi pesan, orang, bahan, alat, teknik, dan lingkungan yang dapat mempengaruhi hasil belajar peserta didik.Pentingnya guru-guru diberikan pelatihan tentang pemahaman dan keahlian kompetensi dalam pembuatan media pembelajaran.

Animasi digunakan dalam media pembelajaran untuk dua alasan.Pertama, untuk menarik perhatian peserta didik dan memperkuat motivasi. Animasi jenis tersebut biasanya berupa tulisan atau gambar yang bergerak-gerak, animasi yang lucu, aneh yang sekiranya akan menarik perhatian peserta didik. Animasi tersebut biasanya tidak ada hubungan dengan materi yang akan diberikan kepada peserta didik. Fungsi yang kedua adalah sebagai sarana untuk memberikan pemahaman kepada peserta didik atas materi yang akan diberikan (Utami, 2007).

Melihat kenyataan yang telah diuraikan, perlu dilakukan suatu kegiatan yang mampu meningkatkan pemahaman dan keterampilan para guru dalam mengembangkan profesionalismenya, khususnya dalam pengembangan media pembelajaran berbasis animasi.Oleh karenanya dilakukan kegiatan pengabdian berupa pelatihan pembuatan media pembelajaran berbasis animasi bagi guruguru di SMA Negeri 1 Air Joman.

\section{METODE}

Metode yang digunakan dalam kegiatan pengabdian adalah metode demonstrasi. Metode demonstrasi digunakan untuk menyajikan materi dengan memperagakan melalui langkahlangkah mengenai suatu proses pembuatan media pembelajaran berbasis animasi. Kemudian dilanjutkan dengan guru-guru ikut mempraktikan secara langsung pembuatan media pembelajaran berbasis animasi tersebut sesuai mata pelajaran yang diajarkan masing-masing.

\section{PEMBAHASAN}

Microsoft Power Point adalah suatu software (program) yang akan membantu dalam menyusun sebuah presentasi yang efektif, professional dan juga mudah. PowerPoint menawarkan dua jenis properti pergerakan, yakni Custom Animations dan Transition. Properti pergerakan Entrance, Emphasis, Exit dan Motion Paths objek dalam sebuah slide dapat diatur pada Menu Animations, sementara Transition mengatur pergerakan dari satu slide ke slide lainnya. Semuanya dapat dianimaskan dalam banyak cara. Desain keseluruhan 
Vol. 1, No. 2, Jul 2018, hlm. $15-18$

ISSN 2614-7912 (cetak)

ISSN 2622-3813 (online)

Available online at http://jurnal.stmikroyal.ac.id/index.php/jurdimas

dari sebuah presentasi dapat diatur dengan menggunakaan Master Slide, dan struktur keseluruhan dari persentasi dapat disunting dengan menggunakan Primitive Outliner (Outline).

Microsoft Power Point akan membantu sebuah gagasan menjadi lebih menarik dan jelas tujuannya. Microsoft Power Point dapat terdiri dari teks, grafik, obyek gambar, clipart, movie, suara dan obyek yang dibuat dengan program lain. Kelebihan fitur PowerPoint adalah :

1. Memiliki tampilan slide per slide untuk mempermudah presentasi.

2. Mudah memasukkan teks dan gambar.

3. Bisa juga memasukkan animasi dan file video dan audio.

4. Bisa mengimpor nilai dari Word dan Excel. 5. Bisa membuat animasi untuk mempercantik proses peralihan antara slide.

6. Memiliki berbagai desain tampilan yang cukup professional untuk bisa diterapkan dengan mudah.

7. Memiliki banyak template presentasi yang bisa digunakan, terutama yang bersifat open source yang tersedia luas di internet.

Berikut adalah tampilan animasi yang sudah bisa dijalankan.

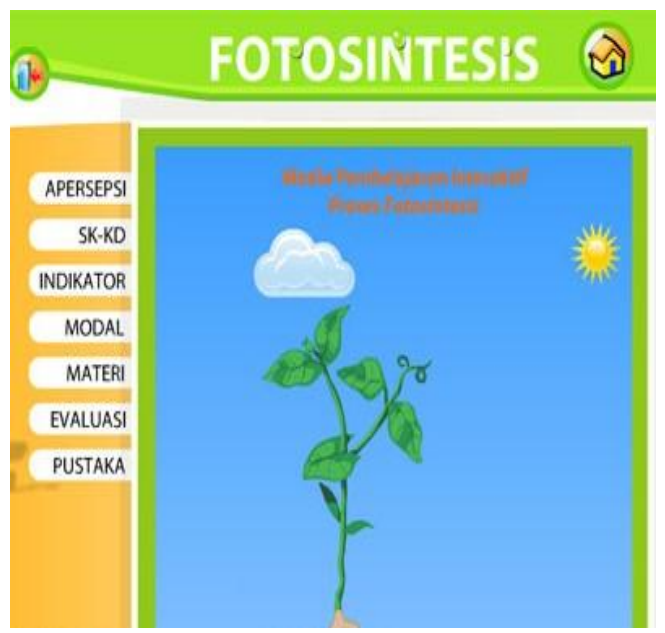

Gambar 1. Tampilan praktek animasi

Berdasarkan diskusi yang dilaksanakan setelah pemapatran materi, dapat dilihat bahwa para guru dapat memahami urgensi pengembangan media pembelajaran, mampu mengenal fungsi program Ms. Power Point, mampu membuat media pembelajaran interktif sesuai dengan bidang/mata pelajaran yang diampu oleh masing-masing guru. Selanjutnya berdasar hasil praktik juga dapat dilihat bahwa para guru mampu mengetahui manfaat program Ms. Power Point dan Wondershare untuk membuat media pembelajaran, mengenal tools Ms. Power Point serta Wondershare dan kegunaannya, Membuat objek shape menyisipkan Objek Movie dan Sound, membuat Efek animasi, membuat Tombol dan mampu membuat media pembelajaran interaktif dengan memanfaatkan program Ms. Power Point.

Foto Kegiatan

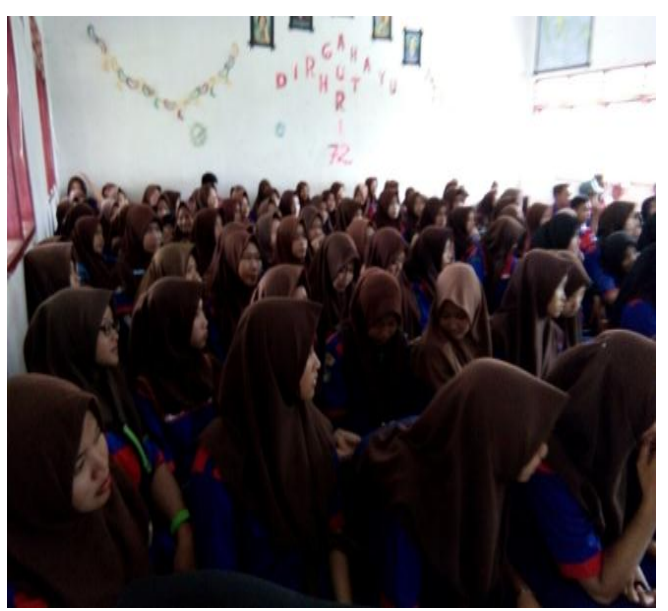

Gambar 2. Foto Siswa yang Menghadiri Pembukaan

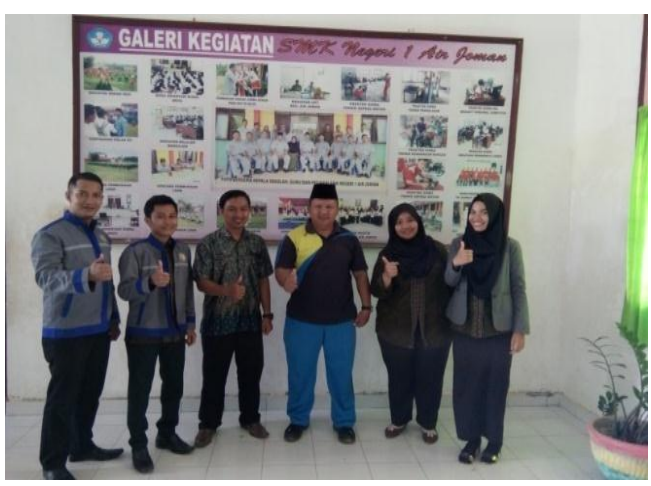

Gambar 3. Foto dengan Kepala Sekolah dan Wakil 
Vol. 1, No. 2, Jul 2018, hlm. $15-18$

ISSN 2614-7912 (cetak)

ISSN 2622-3813 (online)

Available online at http://jurnal.stmikroyal.ac.id/index.php/jurdimas

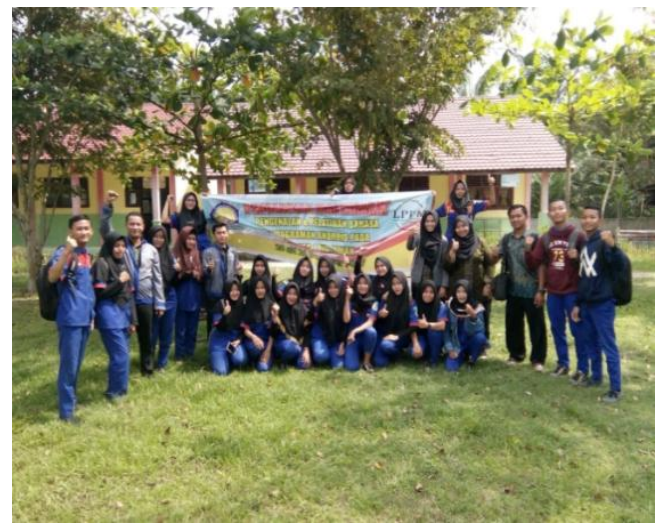

Gambar 4. Foto Bersama Setelah Penutupan

\section{SIMPULAN}

Berdasarkan hasil pelaksanaan kegiatan yang telah dilakukan dapat disimpulkan dengan adanya pelatihan animasi ini, guru-guru dapat menyajikan media pembelajaran yang lebih interaktif dan guru-guru bisa mendapatkan ilmu baru dalam penyampaian materi pembelajaran.

\section{UCAPAN TERIMA KASIH}

Ucapan terimakasih disampaikan kepada semua kalangan yang terlibat dalam kegiatan pengabdian ini. Kepada Kepala Sekolah SMKN 1 yang telah memberikan izin dan tempat untuk mengadakan pengabdian dan kepada ketua yayasan STMIK Royal kisaran yang telah bersedia memberikan dana untuk kelancaran kegiatan pengabdian masyarakat ini. Tidak lupa pula kepada LPPM STMIK Royal dan dosen-dosen lainnya yang terlibat sehingga kegiatan pengabdian masyarakat ini berjalan sebagaimana mestinya.

\section{DAFTAR PUSTAKA}

Anderson, Ronald A. 1994. Pemilihan

dan Pengembangan Media untuk Pembelajaran, terjemahan oleh Yusufhadi Miarso, dkk. Jakarta: PT. Raja Grafindo Persada.

Arsyad, A. 2004. Media Pembelajaran. Jakarta : PT.Raja Grafindo Persada.

Rusman. 2012. Belajar dan Pembelajaran

Berbasis Komputer. Bandung : Alfabeta.Anonim3. (2011).

Utami, D. 2007. Animasi dalam Pembelajaran. www.uny.ac.id/ akademik/ default.php 